\title{
LEVANTAMENTO FITOSSOCIOLÓGICO DE PLANTAS DANINHAS EM ÁREAS DE CULTIVO DE CAFÉ LOCALIZADAS NO SUL DO ESTADO DO ESPIRITO SANTO
}

\author{
Sandy Queiroz Espinoso ${ }^{1}$ \\ Richardson Sales Rocha ${ }^{2}$ \\ Louslany Almeida Oliveira ${ }^{3}$ \\ Eduardo Sudre Pereira ${ }^{4}$ \\ Maurício Novaes Souza ${ }^{5}$ \\ Ismael Lourenço de Jesus Freitas ${ }^{6}$
}

Resumo: O experimento foi realizado em três propriedades de altitude e manejo diferentes, com lavouras de café, localizadas em três comunidades de Alegre, ES, Brasil. Para identificação e quantificação das espécies de plantas daninhas, foi utilizado como unidade amostral um quadrado inventário de $25 \times 25 \mathrm{~cm}$ lançado aleatoriamente. As espécies presentes no seu interior foram cortadas rente ao solo, acondicionadas em sacos plásticos e levadas para o laboratório, para contagem e identificação. A partir dos resultados, determinaram-se os parâmetros fitossociológicos: densidade absoluta (Da), densidade relativa (Dr), frequência absoluta $(F a)$, frequência relativa $(F r)$, dominância absoluta $(D o A)$, dominância relativa $(D o R) e$ o índice de valor de importância (IVI). Com relação às diferenças encontradas entre os parâmetros fitossociológicos para as áreas avaliadas, conclui-se que o levantamento fitossociológico é de fundamental importância para o planejamento do manejo das plantas daninhas.

Palavras-chave: Fitossociologia; Frequência; Identificação; Agricultura.

\footnotetext{
1 Tecnologia em Cafeicultura/Instituto Federal do Espírito Santo - Campus de Alegre, Brasil. E-mail: sandyespinoso@gmail.com.

2 Instituto Federal do Espírito Santo Campus de Alegre, Brasil. E-mail: richardsonsales2016@gmail.com.

${ }^{3}$ Licenciatura em Ciências da Natureza/Instituto Federal Fluminense - Campus Campos Centro, Brasil. E-mail: almeidalouslany@gmail.com.

${ }^{4}$ Instituto Federal do Espírito Santo Campus de Alegre, Brasil. E-mail: eduardo_sudre@hotmail.com.

5 Instituto Federal do Espírito Santo Campus de Alegre, Brasil. E-mail: mauriciosnovaes@yahoo.com.br.

${ }^{6}$ Orientador/Instituto Federal do Espírito Santo - Campus de Alegre, Brasil. E-mail: ismaelljf@yahoo.com.br.
} 